\title{
Comparative genome analysis of central nitrogen metabolism and its control by GlnR in the class Bacilli
}

Tom Groot Kormelink 1,2,3,5, Eric Koenders ${ }^{5}$, Yanick Hagemeijer ${ }^{5}$, Lex Overmars ${ }^{2,4,5}$, Roland J Siezen 1,2,4,5, Willem $\mathrm{M}$ de Vos $^{2,3}$ and Christof Francke ${ }^{1,2,4,5^{*}}$

\begin{abstract}
Background: The assimilation of nitrogen in bacteria is achieved through only a few metabolic conversions between alpha-ketoglutarate, glutamate and glutamine. The enzymes that catalyze these conversions are glutamine synthetase, glutaminase, glutamate dehydrogenase and glutamine alpha-ketoglutarate aminotransferase. In low-GC Gram-positive bacteria the transcriptional control over the levels of the related enzymes is mediated by four regulators: GlnR, TnrA, GltC and CodY. We have analyzed the genomes of all species belonging to the taxonomic families Bacillaceae, Listeriaceae, Staphylococcaceae, Lactobacillaceae, Leuconostocaceae and Streptococcaceae to determine the diversity in central nitrogen metabolism and reconstructed the regulation by GInR.

Results: Although we observed a substantial difference in the extent of central nitrogen metabolism in the various species, the basic GInR regulon was remarkably constant and appeared not affected by the presence or absence of the other three main regulators. We found a conserved regulatory association of $\mathrm{GlnR}$ with glutamine synthetase ( $g / n R A$ operon), and the transport of ammonium ( $a m t B-g \ln K)$ and glutamine/glutamate (i.e. via $g / n Q H M P, g / n P H Q$, gltT, alsT). In addition less-conserved associations were found with, for instance, glutamate dehydrogenase in Streptococcaceae, purine catabolism and the reduction of nitrite in Bacillaceae, and aspartate/asparagine deamination in Lactobacillaceae.

Conclusions: Our analyses imply GInR-mediated regulation in constraining the import of ammonia/amino-containing compounds and the production of intracellular ammonia under conditions of high nitrogen availability. Such a role fits with the intrinsic need for tight control of ammonia levels to limit futile cycling.
\end{abstract}

\section{Background}

The assimilation and re-distribution of nitrogen within a cell is essentially controlled within the central metabolic conversions between alpha-ketoglutarate, glutamate and glutamine (Figure 1A). The enzymes that catalyze these conversions are glutamine synthetase (GS), glutaminase (G), glutamate dehydrogenase (GDH) and glutamine alphaketoglutarate aminotransferase (GOGAT). On a short timescale, the enzyme activity is controlled via activating and inhibitory molecular interactions. For instance, the activity of GS is suppressed via feedback inhibition (FBI-GS) by the

\footnotetext{
* Correspondence: c.francke@cmbi.ru.nl

'Kluyver Centre for Genomics of Industrial Fermentation, P.O. Box 5057, 2600 GA Delft, The Netherlands

${ }^{2}$ TI Food and Nutrition, P.O. Box 557, 6700 AN Wageningen, The Netherlands Full list of author information is available at the end of the article
}

product glutamine and by AMP [1]. Under conditions of nitrogen limitation a high GS activity is maintained to ensure a sufficient level of glutamine [2,3]. On a longer timescale, the enzyme levels are controlled via the activity of a limited number of transcription regulators.

Marked differences exist in the transcription control of the genes encoding the enzymes involved in central nitrogen metabolism across the bacterial kingdom. In the Grampositive model organism Bacillus subtilis, the expression of these genes is mediated by four major transcription factors: CodY, GlnR, TnrA [4] and GltC [5,6]. Of these, GlnR, TnrA and GltC are specific for nitrogen metabolism whereas the global regulator CodY is linked to both carbon and nitrogen metabolism [7]. GltC is specifically associated with the control of the genes encoding glutamine alphaketoglutarate aminotransferase. The transcription factor

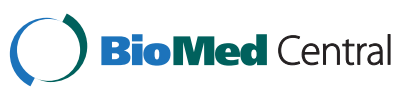



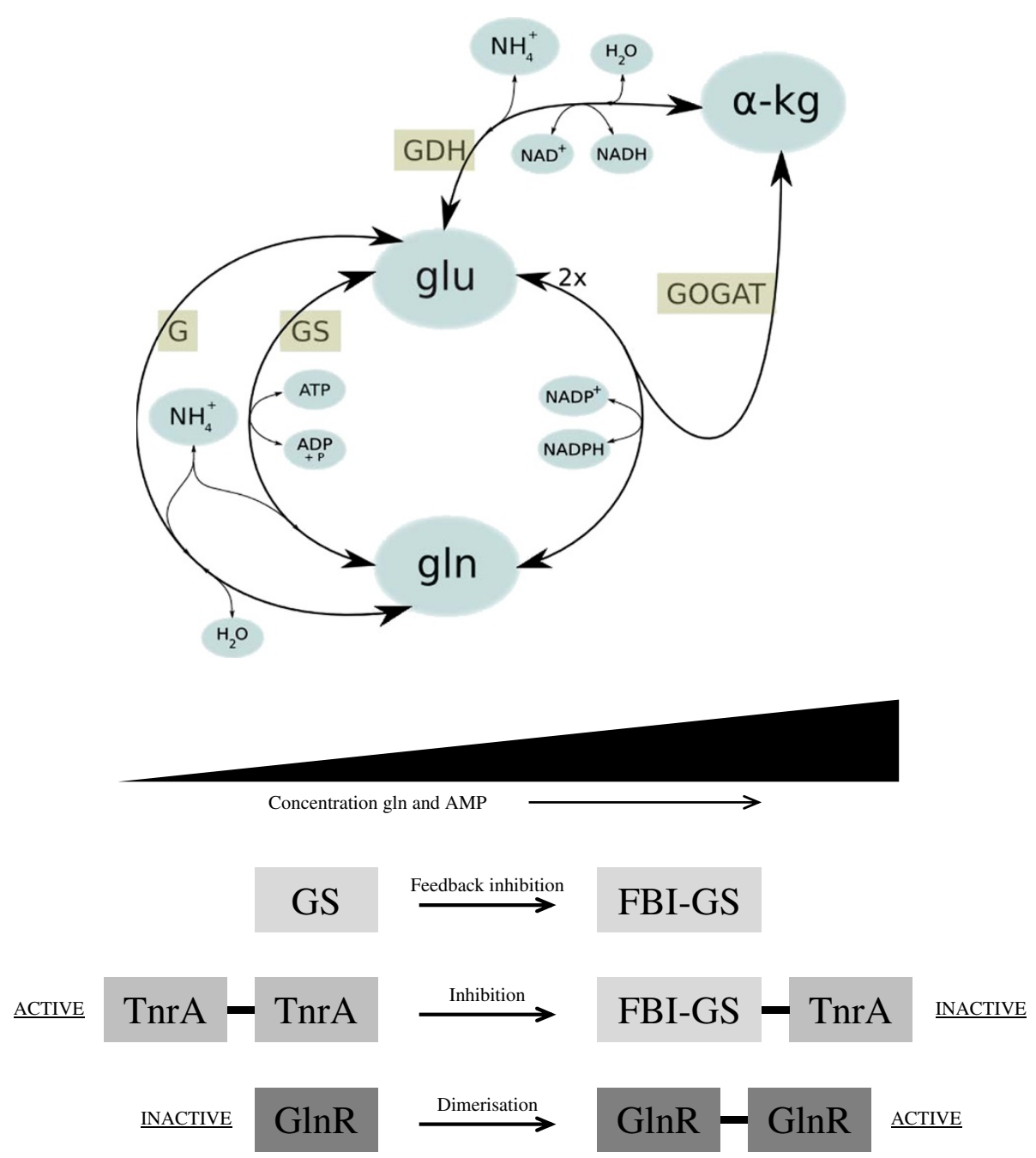

Figure 1 The central reactions of cellular nitrogen metabolism and the related enzymes. (A) and the physiological range of regulator activity and associated feedback mechanisms (B). A) The metabolites are given in blue and the enzymes in green. Abbreviations: alpha-kg, alpha-ketoglutarate; glu, glutamate; gln, glutamine; GS, glutamine synthetase; GOGAT, glutamine alpha-ketoglutarate aminotransferase; GDH, glutamate dehydrogenase; G, glutaminase. B) Glutamine synthetase (GS) is feedback inhibited (FBI-GS) by glutamine and AMP. In the presence of FBI-GS, GInR has a higher affinity for the binding site, whereas the activity of TnrA is repressed through a physical interaction with FBI-GS.

GlnR is active during growth with excess nitrogen, whereas TnrA is active during nitrogen-limiting growth [4]. The change in activity of these transcription factors is affected directly by GS and feedback inhibition (FBI) of the enzyme (Figure 1B). In B. subtilis GlnR is activated in the presence of FBI-GS [8] and TnrA is inhibited through a physical interaction with FBI-GS $[2,9]$. It was also shown that TnrA binds to the PII-like regulatory protein GlnK, which is sensitive to ATP, $\mathrm{Mg}^{2+}$ and alpha-ketoglutarate $[9,10]$. The two proteins become tightly associated with the ammonium permease AmtB at a low level of ATP. In Streptococcus mutans cross-linking and pull-down assays demonstrated that GlnR also interacts with GlnK and that the interaction enhances the binding of GlnR to its cognate site upstream of the $g \ln R A$ operon [11].
In B. subtilis and many other low-GC Gram-positives the genes encoding GlnR $(g \ln R)$ and GS $(g \ln A)$ constitute the operon $g \ln R A$ [12]. In B. subtilis $G \ln R$ was reported to repress the transcription of the $g \ln R A$ operon (negative autoregulation), and of $\operatorname{tn} A$ [13] and the urease gene cluster (ureABC) [14]. On the other hand, TnrA was reported to affect the transcription of a larger set of genes/operons [15], for instance activating $g \ln Q H M P$ (encoding a glutamine $\mathrm{ABC}$ transport system [16]), amtB-glnK (i.e. $\operatorname{nrg} B A$; encoding an ammonium permease and the regulatory protein $G \ln K$ [17]), nas $A$ and nas $B C / D E F$ (encoding proteins related to nitrite reduction [18]), gabP (encoding a gamma amino butyrate transporter [19]) and pucR (encoding the purine catabolism regulator [20]), while repressing alsT (encoding an $\mathrm{H}^{+} / \mathrm{Na}^{+}$amino 
acid symporter [15]), gltAD (encoding glutamate synthase $[21,22]$ ) and ilvBHC-leuABCD (encoding branched-chain amino acid biosynthesis proteins [23]). Similarly, in the oral Streptococci S. pneumonia and S. mutans GlnR was reported to repress the transcription of the $g \ln R A$ operon and of the $g \ln P Q$ operon (encoding another glutamine $\mathrm{ABC}$ transport system) in both organisms and of $g d h$ (encoding glutamate dehydrogenase) in the former, and the $a m t B-g \ln K$ and $c i t B Z$-idh operons (encoding aconitate hydratase, citrate synthase and isocitrate dehydrogenase [24]) in the latter organism [25,26].

Comparative genome analyses have shown that GlnR, TnrA and CodY are characteristic for the low-GC Grampositive species although their distribution is not uniform. For instance, whereas GlnR is found in almost all Bacillus species, TnrA has been identified only in a few. It is an intriguing question whether in the absence of one of these main regulators the others take over its role. We therefore decided to extend (i.e. from 16 to 173 genomes) a previous comparative analysis reported by [27] to identify the presence of the regulators and the genes they regulate in the low GC Gram-positive species of the class Bacilli. This class includes the well-studied families Bacillaceae, Listeriaceae, Staphylococcaceae, Lactobacillaceae, Leuconostocaceae and Streptococcaceae.

We have redefined the binding motifs of GlnR and TnrA on basis of the available experimental and sequence data and used them to identify their respective regulons anew. For that purpose we have applied a footprinting approach formulated earlier by us [28] and a similar motif search procedure [29]. The difference in composition of the GlnR regulon was compared for the various taxonomic families within the class Bacilli and for species having only GlnR or also additional regulators. For most families we found a rather stable composition of the GlnR regulon and some species-specific connections, independent of the presence or absence of the other two regulators. The data imply that GlnR-mediated regulation serves predominantly to limit the import of ammonia/amino-containing compounds and, at the same time, to limit the production of intracellular ammonia.

\section{Results and discussion}

Presence/absence analysis of the genes encoding the central enzymes and regulators

We identified the orthologs of the genes encoding the enzymes of central nitrogen metabolism (G, GS, GDH and GOGAT), the related transport systems and the regulators CodY, GlnR and TnrA, in the sequenced genomes of species related to the class Bacilli on basis of BLAST searches with the sequences of experimentally verified proteins (see methods for details). In Tables 1 and 2 the analysis results for representative species of the orders Bacillales and Lactobacillales, respectively, are presented; the results for the complete set of analyzed species are given in Additional file 1. We observed a clear distinction in gene content between the two orders and between the different taxonomic families within the orders.

Remarkably, within the family Lactobacillaceae, Lactobacillus acidophilus and its close relatives lack all three regulators. There are only three other species, Bacillus halodurans, Bacillus clausii and Bacillus selenitrireducens that lack a gene encoding GlnR. The global regulator CodY is present in most species except for those of the families Lactobacillaceae and Leuconostocaceae. TnrA is only present in species of the order Bacillales within the families Bacillaceae, Paenibacillaceae and the genus Exiguobacterium with the exception of the species and strains of the Bacillus cereus group, Alicyclobacillus acidocaldarius, Brevibacillus brevis and Lysinibacillus sphaericus.

Similarly, we observed a large variation in the presence of the enzymes of central nitrogen metabolism, but much less so in the related transport systems. The set of enzymes is complete within the family of the Bacillaceae and mostly reduced in the other families; in many of the Lactobacillaceae, Leuconostocaceae and Streptococcaceae only glutamine synthetase and one of the other enzymes is present. In the case of transport, at least one ammonium transporter AmtB (Amt-family; 1.A.11 in TCDB classification [42]), also referred to as NrgA [40], is present in most species, although the transporter is absent in more than half of the analyzed Streptococcaceae, in three Bacillus anthracis strains, in the gutrelated Lactobacilli (e. g. L. johnsonii and L. gasseri) and in some meat-related species (e.g. Lactobacillus sakei and Staphylococcus carnosus, Macrococcus caseolyticus). It was recently put forward that transport of ammonia $\left(\mathrm{NH}_{4}^{+}\right)$should be active and tightly regulated to limit futile cycling [43]. This control was suggested to be exerted by the small PII-like regulator GlnK, earlier referred to as $\mathrm{NrgB}$ (and as $\mathrm{GlnB}$ in e.g. L. lactis); the corresponding genes are indeed found genetically associated to $a m t B$ in many of the analyzed species. However, at the same time, it is absent in many others, including all analyzed Lactobacillaceae. Moreover, GlnK was shown to interact with TnrA in B. subtilis $[9,10]$ and GlnR in $S$. mutans [11].

Most of the analyzed species carry one operon encoding a glutamine $\mathrm{ABC}$ transporter (PAAT-family; 3.A.1.3). Two variants of this system were identified: i) a $g \ln Q H M P$ operon found in Escherichia coli and B. subtilis and ii) a $\operatorname{gln} P^{H} Q$ variant found in the Lactobacilli and Streptococci. This latter operon consists of 2 genes, in which $g \ln P^{H}$ represents a fusion-gene of the permease $g \ln P$ and the substrate-binding protein encoding $g \ln H$. In fact, in the case of the Streptococci the substrate-binding domain was duplicated to generate a $g \ln P^{H H} Q$ variant, whereas in some Lactobacilli the $g \ln P^{H}$ gene has been duplicated. The E. coli 
Table 1 Distribution and GInR-mediated regulation of genes related to central nitrogen metabolism within the order Bacillales

\begin{tabular}{|c|c|c|c|c|c|c|c|c|c|c|c|c|c|c|c|c|c|}
\hline NCBI PROJECT NAME \GENES & $\operatorname{cod} Y$ & $\operatorname{tnr} A$ & $g \ln R$ & $g \ln A$ & $g d h$ & $b d h$ & $\begin{array}{l}\text { glutamin- } \\
\text { ase }(H A)\end{array}$ & $\begin{array}{l}\text { glutamin- } \\
\text { ase (LA) }\end{array}$ & glt $A B$ & glt $A^{B C}$ & glts & $a m t B$ & $g \ln K$ & $g \ln Q H M P$ & $g \ln P^{H} Q$ & $\begin{array}{l}g \ln T, \text { als } T, \\
\text { yrbD, yflA }\end{array}$ & $\begin{array}{l}\text { gltP, } \operatorname{dct} A, \text { glt } T, \\
\text { yhcL, nqt }\end{array}$ \\
\hline \multicolumn{18}{|l|}{ A) order Bacillales } \\
\hline Anoxybacillus flavithermus WK1 & 1 & 1 & $\underline{1}$ & $\underline{2(2)}$ & 2 & 1 & & & 1 & 1 & & $1^{d}$ & & & 1 & $2(1)$ & 1 \\
\hline Geobacillus kaustophilus HTA426 & 1 & 1 & 1 & $2(1)$ & 2 & 2 & 1 & & 1 & & & $\underline{1}^{d}$ & & 1 & 1 & 1 & 2 \\
\hline G. thermodenitrificans NG80-2 & 1 & 1 & 1 & $\underline{2(2)}$ & 2 & 2 & 1 & & 1 & & & $\underline{1}^{d}$ & & & 1 & 1 & $5(1)$ \\
\hline G. sp. Y412MC61 & 1 & 1 & 1 & $2(1)$ & 2 & 2 & 1 & & 1 & & & $\underline{\mathbf{2}}^{\mathrm{d}}$ & $\underline{1}$ & 1 & 1 & 1 & 2 \\
\hline G. sp. C56-T3 & 1 & 1 & 1 & $2(1)$ & 2 & 1 & 1 & & 1 & & & $\underline{1}^{d}$ & & 1 & 1 & 1 & 2 \\
\hline G. sp. WCH70 & 1 & 1 & 1 & $\underline{1}$ & 2 & 1 & 1 & & 1 & 1 & & & & 1 & & 1 & 3 \\
\hline Bacillus cereus ATCC 14579 & 1 & & $\underline{1}$ & $\underline{1}^{b}$ & 1 & 1 & 1 & 1,0 & & 1 & 1 & $\underline{1}$ & & 1,2 & & $6(1)$ & $5(1)$ \\
\hline B. anthracis str. Ames & 1 & & $\underline{1}$ & $\underline{1}$ & 1 & 1 & 1 & 1 & & 1 & 1 & $\underline{0,1}$ & & 1 & & $6(1)$ & $5(1)$ \\
\hline B. thuringiensis str. Al Hakam & 1 & & 1 & $\underline{1}$ & 1 & 1 & 1 & 1 & & 1 & 1 & $\underline{1}$ & & 1 & & $7(1)$ & $6(1)$ \\
\hline B. weihenstephanensis KBAB4 & 1 & & $\underline{1}$ & $\underline{1}$ & 2 & 1 & 1 & & & 1 & 1 & $\underline{1}$ & & 1 & & $6(1)$ & $5(1)$ \\
\hline B. atrophaeus 1942 & 1 & $\underline{1}$ & $\underline{1}$ & $\underline{1}$ & 3 & 1 & 1 & 1 & 1 & & 1 & 1 & $\underline{1}$ & $\underline{1}$ & & $3(1)$ & 4 \\
\hline B. amyloliquefaciens DSM7 & 1 & $\underline{1}$ & $\underline{1}$ & $\underline{1}$ & 2 & 1 & 1 & $1^{c}$ & 1 & & 1 & $\underline{1}$ & 1 & 1 & & $2(1)$ & 3 \\
\hline B. pumilus SAFR-032 & 1 & 1 & $\underline{1}$ & $\underline{1}$ & 2 & 1 & 1 & 1 & 1 & & 1 & $\underline{1}$ & $\underline{1}$ & 1 & & 3 & $5(1)$ \\
\hline B. subtilis str. 168 & 1 & 1 & 1 & $\underline{1}$ & 2 & 1 & 1 & 1 & 1 & & 1 & $\underline{1}$ & $\underline{1}$ & 1,0 & & $4(1)$ & 4 \\
\hline B. licheniformis ATCC 14580 & 1 & $\underline{1}$ & $\underline{1}$ & $\underline{1}$ & $2(1)$ & 1 & 1 & 1 & 1 & & & 2(1) & $2(1)$ & & & $6(1)$ & 4 \\
\hline B. megaterium DSM319 & 1 & 1 & $\underline{1}$ & $\underline{1}$ & 3 & 1 & & 1 & 1 & & 1 & $\underline{2(2)}$ & $\underline{2(2)}$ & 1 & & $3(1)$ & $11(1)$ \\
\hline B. pseudofirmus OF4 & 1 & $\underline{1}$ & $2(1)^{\mathrm{e}}$ & $\underline{2(2)}$ & 4 & 1 & 1 & 1 & 1 & & & $\underline{1}$ & & & 1 & $3(1)$ & 3 \\
\hline B. clausii KSM-K16 & 1 & 1 & & 2 & 2 & 1 & 1 & & 1 & & & 1 & & & 1 & 3 & 3 \\
\hline B. halodurans C -125 & 1 & 1 & & 2 & 5 & 2 & 1 & 1 & 1 & & & 1 & & & & 5 & 1 \\
\hline B. selenitireducens MLS1O & 1 & 1 & & 1 & 4 & 1 & & 1 & $1^{\mathrm{b}}$ & 1 & & 1 & & & 1 & 2 & \\
\hline Lysinibacillus sphaericus C3-41 & 1 & & $\underline{1}$ & $\underline{2(2)}^{\mathrm{c}}$ & 2 & 1 & & & & & & $\underline{1}$ & $\underline{1}$ & & 1 & 3 & 5 \\
\hline Oceanobacillus iheyensis HTE831 & 1 & $1^{a}$ & $\underline{1}$ & $\underline{1}$ & 1 & 2 & & 1 & 1 & & 1 & $\underline{1}$ & $\underline{1}$ & & 1 & 3 & 3 \\
\hline Exiguobacterium sp. AT1b & 1 & 1 & 1 & $2(1)$ & 1 & 1 & 1 & & 1 & & 1 & $\underline{1}$ & & & & $6(1)$ & 1 \\
\hline Paenibacillus polymyxa E681 & & $\underline{1}$ & $\underline{1}$ & $2(1)$ & 1 & & 1 & & 1 & & & $\underline{1}^{d}$ & & $2(1)$ & 1 & 2 & 2 \\
\hline Pb. sp. JDR-2 & 1 & 1 & 1 & $\underline{2(1)}$ & 2 & 1 & 1 & & 1 & & 1 & $3\left(1^{d}\right)$ & 1 & 1 & & & 1 \\
\hline Brevibacillus brevis NBRC 100599 & 1 & & 1 & $\underline{2(2)}$ & 2 & 1 & 1 & 1 & $1^{\mathrm{b}}$ & & 1 & $\underline{1}^{d}$ & & 1 & 1 & 1 & 3 \\
\hline Ab. acidocaldarius DSM 446 & 1 & & 1 & $3(1)$ & 2 & 1 & & & & 1 & & $2(1)$ & 1 & & & & \\
\hline Listeria innocua Clip11262 & 1 & & $\underline{1}$ & 1 & 1 & & & & 1 & & & $\underline{1}$ & $\underline{1}$ & & 1 & & \\
\hline L. monocytogenes EGD-e & 1 & & $\underline{1}$ & $\underline{1}$ & 1 & & & & 1 & & & $\underline{1}$ & $\underline{1}$ & & 1 & & \\
\hline L. seeligeri 1/2b str. SLCC3954 & 1 & & $\underline{1}$ & $\underline{1}$ & 1 & & & & 1 & & & $\underline{1}$ & $\underline{1}$ & & 1 & & \\
\hline Staphylococcus aureus Mu50 & 1 & & 1 & $\underline{1}$ & 1 & & & & 1 & & 1 & 1 & & & $\underline{1}$ & 2 & 2 \\
\hline
\end{tabular}


Table 1 Distribution and GInR-mediated regulation of genes related to central nitrogen metabolism within the order Bacillales (Continued)

\begin{tabular}{lllllllll}
\hline S. carnosus TM300 & 1 & $\mathbf{1}$ & $2(1)$ & 1 & 1 & 1 & 3 \\
S. epidermidis ATCC 12228 & 1 & $\mathbf{1}$ & $\mathbf{1}$ & 1 & 1 & 1 & $\mathbf{1}$ & 1 \\
S. haemolyticus JCSC1435 & 1 & $\mathbf{1}$ & $\mathbf{1}$ & 1 & 1 & $\mathbf{1}$ & 1 \\
S. lugdunensis HKU09-01 & 1 & $\mathbf{1}$ & $\mathbf{1}$ & 1 & 1 & 1 & $\mathbf{1}$ & 1 \\
S. saprophyticus ATCC 15305 & 1 & $\mathbf{1}$ & $\mathbf{1}$ & 2 & 1 & 1 & $\mathbf{1}$ & 2 \\
Mc. caseolyticus JCSC5402 & 1 & $\mathbf{1}$ & $\mathbf{1}$ & 1 & 1 & & $2(1)$ & 2 \\
\hline
\end{tabular}

The table summarizes the data retrieved for all species and strains which can be found in Additional file 1. The number of orthologs/homologs in every genome is indicated. For instance Anoxybacillus flavithermus WK1 contains 2 genes encoding glutamine synthetase. Every species is represented by one strain only. Species abbreviations: Ab., Alicyclobacillus; B., Bacillus; G., Geobacillus; L., Listeria; Mc., Macrococcus; Pb. Paenibacillus; S., Staphylococcus.

Gene content. The included genes encode the established regulators CodY, TnrA and GInR [4]; the central enzymes Gln synthetase ( $g / n A$; [30]), Glu dehydrogenase (gdh; [31,32]), 3-hydroxybutyrate dehydrogenase (bdh [33,34]), high affinity (HA) and low affinity (LA) glutaminase, glutamate synthase (NADPH-dependent, large and small subunit gltB and gltA [21,22]; B. cereus type gltt; ferredoxin dependent glts [35]), aspartateammonia ligase/asparagine synthetase (asnA [36] or asnB [37]), asparaginase (ansA or ansZ [38,39]); and the transport systems for ammonium (amtB with related regulator glnK; [40]), gln/glu using ATP (ABC-family, $g / n P^{H} Q$ and $g / n Q H M P$ ) and glutamine-like proton symport (AGCS-family, $g / n T$, alsT, yrbD, yflA) and glutamate-like proton symport (DAACS-family, gltP, gltt, yhcl, nqt). In the latter two cases a variation in numbers was observed for different strains. In the other cases the numbers were far less variable (the ones that were variable are indicated as comma separated numbers).

GInR-mediated regulation. Genes/operons that have a clear upstream GlnR binding site are marked by dark grey boxes (similarity score $>87 \%$ ), whereas genes/operons that are preceded by a less clear site are marked light grey (similarity score $80-87 \%$ ). In case more genes are present encoding the same function then the number of genes with a clear binding site is indicated between brackets and if in addition the other gene(s) are preceded by a less clear site then the cell is marked light grey.

a) A GlnR-binding site is present but downstream of tnrA because the gene has opposite direction when compared to all other species.

b) For one sequence no ORF was called. However the gene could be identified using tBLASTN.

c) One of the sequences in two fragments.

Ceems part of an operon that includes a gene with DUF294 domain and the gene dnaQ.

e) The $g / n R$ and $g / n A$ duplicates in B. pseudofirmus OF4 are not part of a single operon and located at different positions on the genome. 
Table 2 Distribution and GInR-mediated regulation of genes related to central nitrogen metabolism within the order Lactobacillales

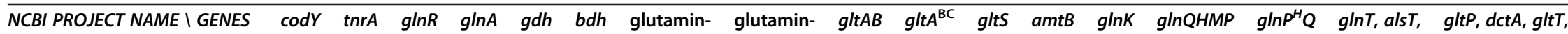
B) order Lactobacillales ase (HA) ase (LA)

Lactobacillus acidophilus NCFM

L. helveticus DPC 4571

L. crispatus STI

L. gasseri ATCC 33323

L. johnsonii F19785

L. bulgaricus ATCC 11842

L. fermentum IFO 3956

L. reuteri JCM 1112

L. brevis ATCC 367

L. plantarum WCFS1

L. salivarius UCC118

L. casei BL23

L. rhamnosus GG

L. sakei $23 \mathrm{~K}$

PC. pentosaceus ATCC 25745

Leuconostoc citreum KM2O

Ln. mesenteroides ATCC 8293

Oenococcus oeni PSU-1

Lactococcus lactis II1403

Streptococcus mutans UA159

S. equi

\begin{tabular}{|c|c|c|}
\hline 1 & $\underline{1}$ & 1 \\
\hline & $\underline{1}$ & \\
\hline & $\underline{1}$ & \\
\hline & $\underline{1}$ & \\
\hline & $\underline{1}$ & \\
\hline & $\underline{1}$ & \\
\hline & $\underline{1}$ & \\
\hline & $\underline{1}$ & \\
\hline & $\underline{1}$ & \\
\hline$\underline{1}$ & $\underline{1}$ & \\
\hline 1 & $\underline{1}$ & 1 \\
\hline$\underline{1}$ & $\underline{1}$ & 1 \\
\hline$\underline{1}$ & $2(1)$ & 1, \\
\hline$\underline{1}$ & $2(1)$ & 1 \\
\hline$\underline{1}$ & $\underline{1}$ & \\
\hline$\underline{1}$ & $\underline{1}$ & \\
\hline$\underline{1}$ & $\underline{1}$ & \\
\hline$\underline{1}$ & $\underline{1}$ & \\
\hline$\underline{1}$ & $\underline{1}$ & \\
\hline 1 & $\underline{1}$ & \\
\hline 1 & $\underline{1}$ & 1 \\
\hline$\underline{1}$ & 1 & 1 \\
\hline$\underline{1}$ & $\underline{1}$ & \\
\hline 1 & $\underline{1}$ & \\
\hline 1 & $\underline{1}$ & \\
\hline 1 & $\underline{1}$ & \\
\hline 1 & $\underline{1}$ & \\
\hline
\end{tabular}

1

3

S. uberis 0140

S. gordonii str. Challis substr. CH1

S. thermophilus CNRZ1066

S. sanguinis SK36

S. pneumoniae $R 6$ 
Table 2 Distribution and GInR-mediated regulation of genes related to central nitrogen metabolism within the order Lactobacillales (Continued)

\begin{tabular}{|c|c|c|c|c|c|c|c|c|c|}
\hline S. mitis B6 & 1 & $\underline{1}$ & $\underline{1}$ & 1 & $\underline{1}$ & 1 & $\underline{1}$ & $\underline{1}^{c}$ & 1 \\
\hline S. agalactiae NEM316 & 1 & $\underline{1}$ & 1 & 1 & 1 & & $\underline{1}$ & $\underline{1}^{c}$ & 1 \\
\hline S. pyogenes M1 GAS & 1 & $\underline{1}$ & 1 & & & & & $\underline{1}^{c}$ & 1 \\
\hline S. suis $B M 407$ & 1 & $\underline{1}$ & 1 & 1 & & & $\underline{1}$ & $\underline{1}^{c}$ & 1 \\
\hline
\end{tabular}

ne content and how GInR-mediated

regulation is indicated see the legend of Table 1. Every species is represented by one strain only. Species abbreviations: L., Lactobacillus; Ln., Leuconostoc; Pc., Pediococcus; S., Streptococcus.

a) L. lactis has a codY paralog named $\operatorname{codZ}[41]$.

b) There is a second $g / n P^{H}$ gene located next to the $g / n P^{H}, Q$ operon.

c) The $g / n P^{H}$ gene encodes two $H$ domains.

d) In $O$. oeni the gene $g \ln P^{H}$ is in one operon with a gene encoding an asparaginase, whereas a $g / n Q$ homolog is missing.

e) In $L$. salivarius a second $g \ln P^{H}$ gene is not part of an operon and is located elsewhere on the genome with respect to the $g \ln P^{H} Q$ operon. 
system has been related to high-affinity glutamine transport [16], whereas the L. lactis system was shown to transport both glutamine and glutamate [44]. Recently, the E. coli-type system present in Streptococcus mutans was proven also to be involved in the transport of glutamate [45]. Remarkably, most of the species of the order Lactobacillales carry a copy of both types (Table 2). These Lactobacilli lack the genes encoding a glutamate dehydrogenase $(g d h)$ or glutamate synthetase $(g l t A B)$. Therefore these species are unable to synthesize glutamate, which makes it essential to have a glutamate transport system.

Most of the analyzed species encode one or more transporters of the DAACS-family (2.A.13) and AGCS-family (2. A.25), with the exception of the species within the families Listeriaceae and Leuconostocaceae, some Lactobacillaceae and L. lactis. These transporter-protein families have been related to the cation symport of dicarboxylates and amino acids. The former family is represented by GltP (glutamate/ aspartate [46]), GltT (glutamate [47]), DctA (C4-dicarboxylates including aspartate [48]), YhcL (or TcyP; cystine [49]) and Nqt (putative glutamate in B. subtilis), whereas the latter family is represented by GlnT (glutamine [50]), AlsT (amino acid [15]), YrbD (putative amino acid) and YflA (putative amino acid).

\section{Identification of a GlnR and TnrA specific binding motif}

The protein sequences of GlnR and TnrA are highly similar and their reported DNA binding sites show little difference [27]. The palindromic consensus sequence has been defined as TGTNA-N7-TNACA [13,15,51-55]. Gel mobility shift assays indicated that TnrA and GlnR indeed bind to the same sites upstream of the $\operatorname{tn} A$ gene and the $g \ln R A$ operon, albeit with different specificity [13]. To achieve a separation of the predicted sites we have employed a genomic footprinting strategy that we formulated previously $[28,56]$ to identify the GlnR-specific binding motif anew. The strategy involved the definition of Groups Of Orthologous Functional Equivalents (GOOFEs) on basis of conserved genomic context. Within these GOOFEs we assumed conservation of binding motif. In all analyzed species that contain $g \ln R$, the genetic association with $g \ln A$ has been conserved. Moreover, for several species GlnR was shown experimentally to be autoregulatory and therefore the upstream region of the $g \ln R A$ operon within all genomes was scanned for a conserved GlnR binding site. In line with earlier published observations we found a clear and strongly conserved binding site 3-6 nucleotides upstream of a putative-35 region (i.e. TTGAC) of the promoter in all analyzed species and a second binding site overlapping the promoter in many of the Bacillus species (Figure 2).

It was shown in a cross-regulation study that the binding site upstream of the promoter of the $g \ln R A$ operon in $B$. subtilis is only involved in GlnR-mediated regulation [13].
Therefore, to tract potential differences between the GlnR and TnrA binding motifs, we used the conserved GlnRbinding sites upstream of the promoter to generate a family specific position frequency matrix (see methods). It appeared that the frequency representations of the motif varied slightly between the Streptococci and the other Bacilli (Figure 3A and B). Both motifs that were generated for $G \operatorname{lnR}$ adhered to the consensus motif [13,15,51-55] and were similar to the motif that was previously defined by [27]. Then, a TnrA-specific motif was created on basis of the TnrA sites upstream of $a m t B$, ans $Z, \operatorname{gap} P, \operatorname{gln} Q$, nas $A$, $n a s B, n a s D, o p p A, p u c J, p u c R, y k z B$ and $y w r D$. These binding sites were reported to relate to transcription activation in B. subtilis $([15,19,38,52,57-59]$ and raw data file 1) and are supposed to be TnrA-specific as GlnR has not been reported to activate transcription. The frequency representation of the TnrA-specific motif is given in Figure 3C. A comparison of the GlnR and TnrA specific motifs shows that there is limited difference. Yet the TnrA motif clearly lacks the conserved $\mathrm{A}$ and $\mathrm{T}$ at the $3^{\prime}$ and $5^{\prime}$ end, as was noted before. In fact, mutation of the conserved $\mathrm{T}$ at the $5^{\prime}$ end to a $\mathrm{C}$ or a $\mathrm{G}$ (but not $\mathrm{A}$ ) was reported to abolish GlnR-mediated repression of the $g \ln R A$ operon in $B$. subtilis [55], although [13] did not observe such an effect. Our new motifs also suggest that there is a slight preference for a $G$ at position 7 and a $C$ at position 13 which is less pronounced in the GlnR motif in Streptococci.

\section{The predicted GInR and TnrA regulon of $B$. subtilis}

The specific GlnR and TnrA motif were used to search the B. subtilis genome for similar sites using the Similar Motif Search (SMS) procedure described in the methods. The results of this search can be found in Additional file 2. Although the differences in GlnR and TnrA motif did not appear strong in first instance, the results of the motif search in B. subtilis suggest they are large enough to bring about some separation between GlnR and TnrA binding sites, in line with the observed variable affinities of these transcription factors for the same sites [13].

In principle the highest scoring sites are likely to be genuine binding sites and by using a relatively high cut-off score of 0.89 the majority $(>70 \%)$ of experimentally validated sites was indeed captured for GlnR as well as for TnrA. Moreover, most other true binding sites scored just below the cut-off. Only 4 out of 22 reported TnrA binding sites were not recovered in this way. Some of the sites were actually found at a relatively large distance from the translation start (e.g. in the case of $i l v B[60]$ ) and many sites were found located in the shared regulatory region of neighboring genes located on opposite strands (so-called divergons). Although many sites were found in both searches, the similarity score was mostly clearly better for one than for the other. Genes/operons predicted to be controlled by both regulators included the known genes/operons $g \ln R A$ 


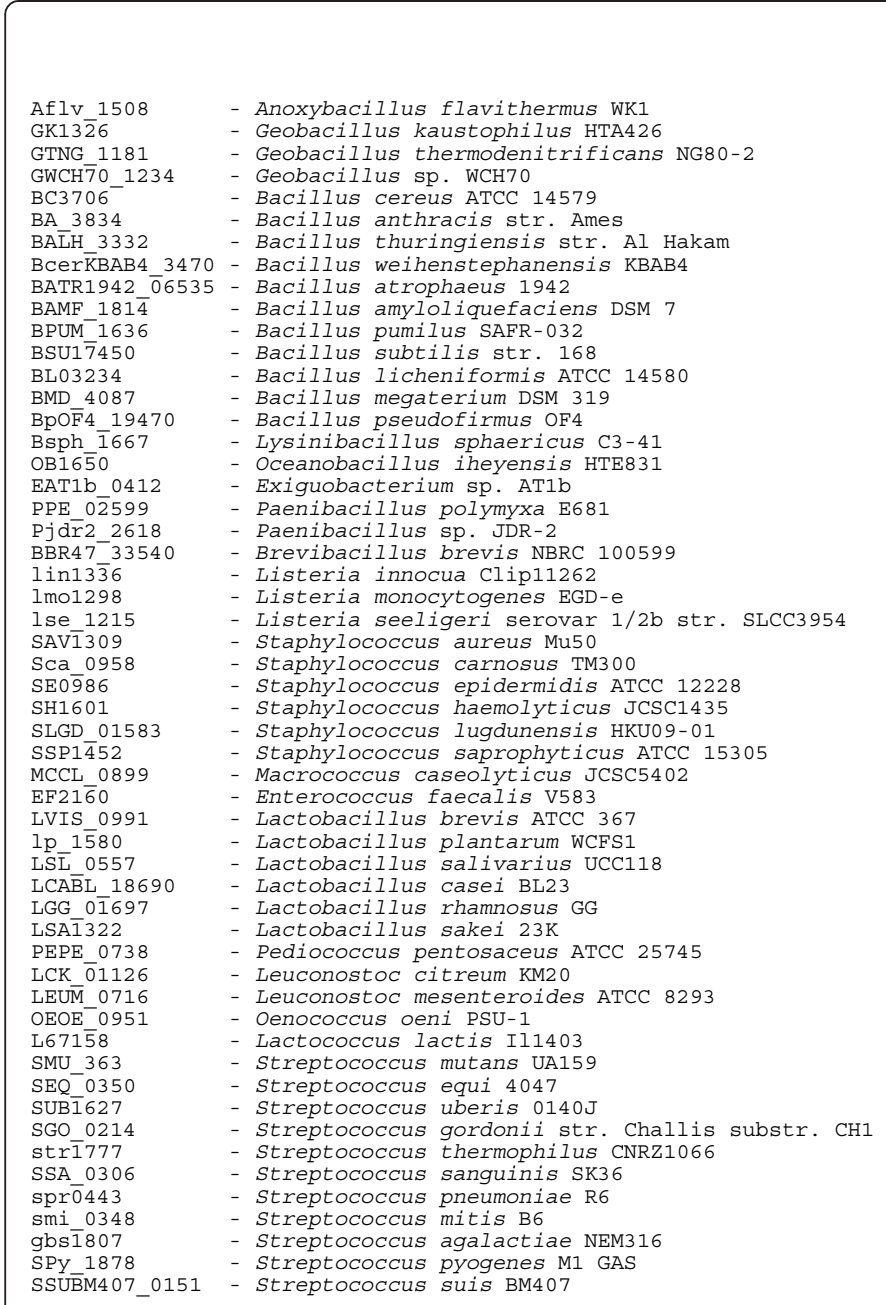

\section{GInR1}

GlnR2

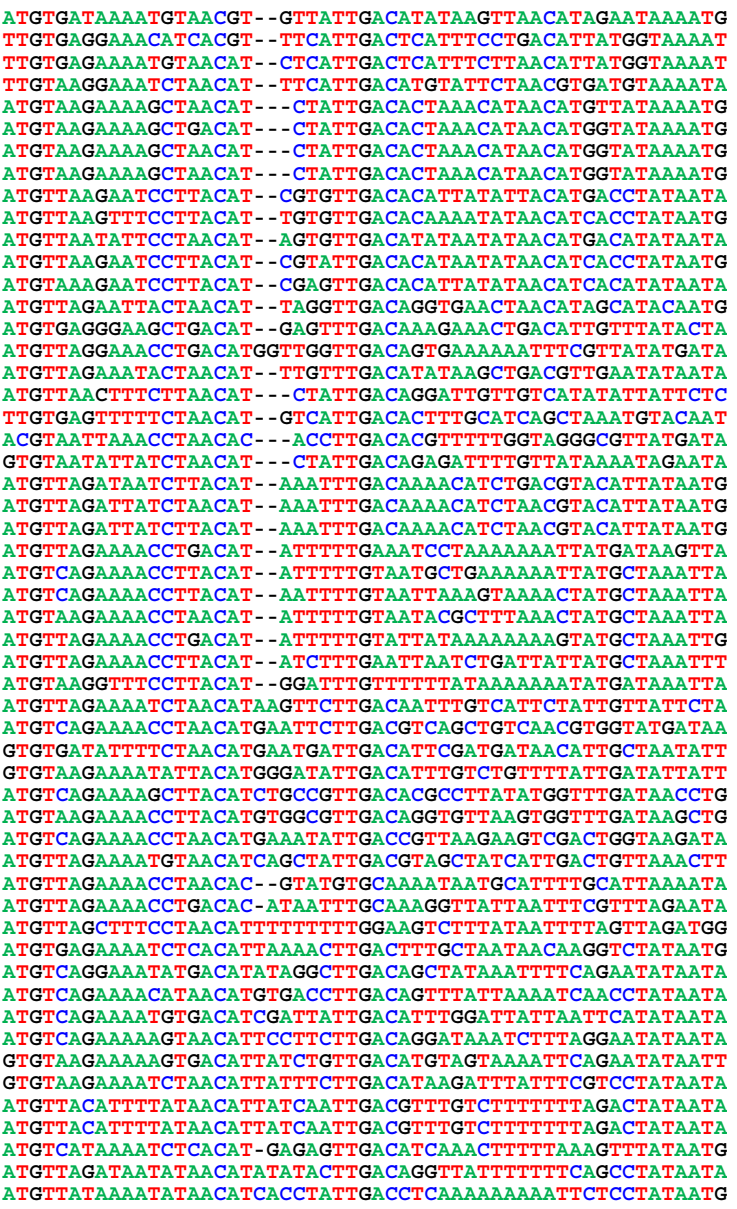

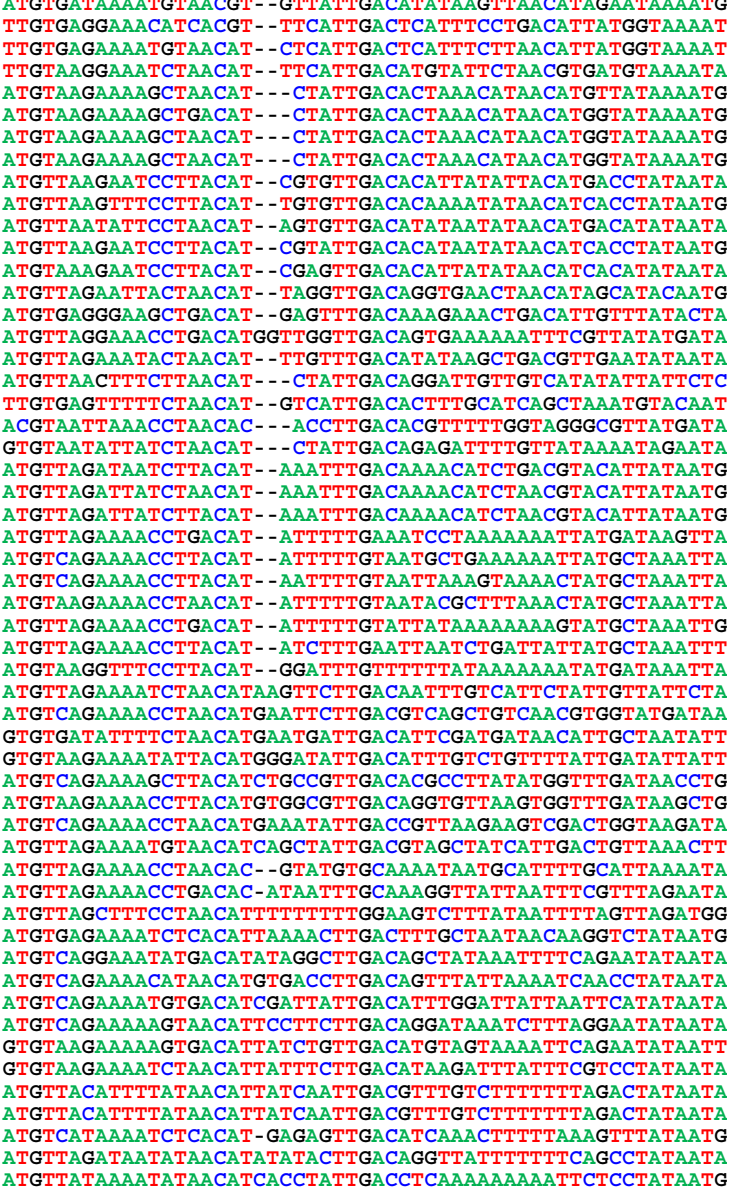
$-35$

Figure 2 Aligned upstream region of the gInRA operon in sequenced Bacilli. The putative GlnR-binding sites and the-35 region (TTGAC) of the promoter are marked.

(glutamine synthesis) and tnrA. Additional shared sites were found upstream of alsT, pucH, pucJKLM and the $a m t B-g \ln K$ operon. Although these sites have not been attributed to GlnR earlier and were described to be activated by TnrA [15,57], the relatively high simililarity score and the evolutionary conservation, also among organisms that lack TnrA, suggest they are true binding sites. In the case of the $a m t B-g \ln K$ operon (import of ammonia) it was formerly concluded that it is not repressed by GlnR on the basis of a singular observation. It was found that the $a m t B-$ $g \ln K$ operon remained repressed in a GlnR deletion mutant (i.e. $\operatorname{gln} R 57$ [12]) in the presence of glutamine, similar to the wild-type [61]. However this observation does not exclude repression by $\mathrm{GlnR}$ in case additional regulators are at play. In fact, in L. lactis it was shown that expression of the $a m t B-g \ln K$ operon is controlled by GlnR but also by CodY [62]. In S. mutans it was shown by electrophoretic mobility shift assay that GlnR binds to the promoter region of both the $g \ln R A$ and $a m t B-g \ln K$ operon [11]. The same study identified GlnK as an activator of GlnR DNAbinding. Besides, the data in Tables 1 and 2 indicate that a putative GlnR-binding site upstream of $a m t B$ is present across almost all species of the class Bacilli. The conservation of these putative binding sites, including the conservation of the flanking $\mathrm{A}$ and $\mathrm{T}$ nucleotides (see Additional file 3), suggests $G \ln R$ represses the $a m t B-g \ln K$ operon in all analyzed species, and thus also in $B$. subtilis.

It was proposed that GlnR lacks the capability to recruit RNA polymerase and therefore acts solely as a repressor [13]. Given this lack of activating/recruiting capacity, it is to be expected that GlnR will only act on the expression of one gene in various divergons, like for instance on $\operatorname{tn} r A$ but not $y k z B$ [58] and on $p u c H$ but not pucR [59]. Moreover, in various cases where TnrA was shown to activate 


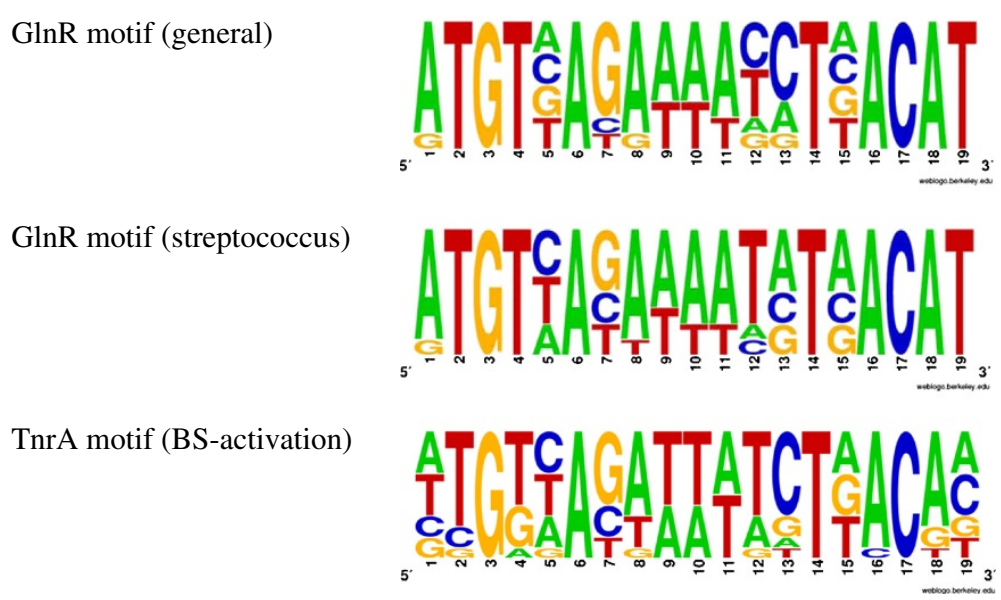

Figure 3 Frequency representation of the putative GInR and TnrA binding motifs. A) GlnR-binding motif in species of the class Bacilli. B) GlnR-binding motif in species of the family Streptococci. C) TnrA-binding motif in Bacillus subtilis.

transcription our analysis suggests the binding site is TnrA-specific, like for $g a b P$, oppABCDF and $g \ln Q H M P$. Other genes/operons that seem to be TnrA-specific in B. subtilis include: $y c l G$, encoding an uronase; $y d a B$, encoding an acyl-CoA ligase; pel, encoding a pectate lyase; braB, encoding a branced-chain amino acid- $\mathrm{Na}+$ symporter; and pucABCDE, encoding a xanthine dehydrogenase operon.

\section{The predicted GInR regulon in oral Streptococci}

GlnR binding-site predictions were performed for the oral Streptococci S. pneumoniae and S. mutans on basis of the Streptococci-specific motif (results in Additional file 4). For S. pneumoniae D39 and S. mutans UA159, the genes/operons predicted to be controlled by GlnR were compared to the genes/operons whose transcription was most affected in a GlnR mutant [25,26]. We found good agreement between prediction and experiment for both organisms (see Table 3). In the case of $S$. pneumoniae D39, the most significantly up-regulated genes/operons, $g \ln P^{H H} Q$ and $g d h$ were represented by the best hits in our analysis. The analysis also revealed the presence of a clear binding site in front of 2 other genes/operons, in line with the predictions of [27]. These included the second glutamine ABC transporter $(g \ln Q H M P)$ and an operon containing enzymes of the urea cycle $(\operatorname{arc} A B)$. The clear regulatory connection between GlnR and the $\operatorname{arc} A B$ operon (encoding arginine deiminase and ornithine carbamoyltransferase) was found in all sequenced S. pneumoniae strains, but was absent in the other species. The absence of a change in $\operatorname{arc} A B$ and $g \ln Q H M P$ expression upon inactivation of $g \ln R$ may be explained by the presence of additional regulatory interactions.

In the case of S. mutans UA159 the genes and operons found to be mostly affected in the knockout mutant [26] were the nrgA-SMU_1657c operon, coding for the ammonium transporter $A m t B$ and its nitrogen regulatory protein GlnK; the citB-citZ-idh operon coding for aconitate hydratase, citrate synthase and isocitrate dehydrogenase; the $g \ln Q H M P$ and $g \ln P^{H H} Q$ operons encoding glutamine $\mathrm{ABC}$ transporters; and Smu.807, coding for a putative membrane protein, which is in a divergon with $g \ln P^{H H} \mathrm{Q}$. The best hits resulting from our analysis are also located upstream of the same operons. Moreover, we found a clear binding site preceding the genes $g d h$ and $t h r C$. The citB-citZ-idh operon has been shown to be essential for glutamate biosynthesis in S. mutans [24].

\section{Conserved genetic associations of GlnR and the effect of the other regulators}

GlnR binding-site predictions were performed for selected genomes that represented all sequenced species of the class Bacilli. We then collected the function annotation of all proteins encoded by genes/operons downstream of a putative GlnR-binding site that fitted the selection criteria (see methods) to generate an overview of the regulatory connections that are conserved between more than three species (accumulated in Additional file 4). The results are summarized in Tables 1, 2 and 4. As expected, we found a conserved regulatory connection between $G \ln R$ and the $g \ln R A$ operon in all analyzed species and with $t n r A$ in all Bacilli. Only in a few species of the order Bacillales the related GlnR-binding sites deviated from the consensus (e.g. in some Geobacillus species). Another connection that was conserved in almost all of the analyzed species was that with $a m t B$ (often $a m t B-g \ln K$ ).

Various additional conserved connections were found, although these appeared far more family-specific. For instance, in the order Lactobacillales a genomic association with the genes of the two glutamine $\mathrm{ABC}$ transporter 
Table 3 Predicted GInR regulon in Streptococcus pneumoniae (A) and Streptococcus mutans (B)

\begin{tabular}{|c|c|c|c|c|}
\hline gene/operon name & locus tag* & annotation & score (rank) & rank in exp. \\
\hline \multicolumn{5}{|c|}{ A) Streptococcus pneumoniae } \\
\hline$g \ln R, A$ & SP_0501,0502 & GlnR regulator, Glutamine synthetase & $0.95(1)$ & k.o. \\
\hline$g \ln P^{H H}, Q$ & SP_1241,1242 & Gln/Glu ABC transport system & $0.92(2)$ & 1,2, SP_1243: 3 \\
\hline$g d h$ & SP_1306 & Glutamate dehydrogenase & $0.90(5)$ & 4 \\
\hline $\operatorname{arc} A, B^{a}$ & SP_2148,2150 & Arginine deiminase, Ornithine carbamoyltransferase & $0.91(3)^{b}$ & - \\
\hline$g \ln Q, H, M, P$ a & SP_0610-0607 & Gln/Glu ABC transport system & $0.84^{\mathrm{b}}$ & - \\
\hline \multicolumn{5}{|c|}{ B) Streptococcus mutans (UA159) } \\
\hline$g \ln R, A$ & Smu. 363,364 & GlnR, Glutamine synthetase & $0.95(1)$ & k.o. \\
\hline$a m t B, g \operatorname{lnK}$ & Smu.1658,1657c & Ammonium transport system, GInK regulator & $0.95(1)$ & 1 \\
\hline$g \ln Q, H, M, P$ & Smu.1519-1522 & Gln/Glu ABC transport system & $0.95(2)$ & 2 \\
\hline citB,Z,idh & Smu. $670,671,672$ & $\begin{array}{l}\text { Aconitate hydratase, Citrate synthase, Isocitrate } \\
\text { dehydrogenase }\end{array}$ & $0.95(1)$ & 3 \\
\hline Smu.807 & Smu.807 & Putative membrane protein & $0.95(1)$ & 4 \\
\hline$g \ln P^{H H}, Q$ & Smu. $806 c, 805 c$ & Gln/Glu ABC transport system & $0.95(1)$ & 5 \\
\hline gdh & Smu.913 & Glutamate dehydrogenase & $0.95(1)$ & - \\
\hline Smu.68, thrC & Smu.68,70 & Hypothetical, Threonine synthase & $0.92(5)$ & - \\
\hline
\end{tabular}

The GlnR-binding site identifications were made as described in the methods for all strains with a published genome (data in Additional file 4). The composition of the regulon appeared identical between strains although the similarity scores of particular binding sites varied slightly. The table lists the numbers obtained with strains TIGR4 and UA159, respectively. Column 4: The ranking is based on the scores obtained with the similar motif search procedure, which provides various sites with identical scores and thus identical ranking. The absence of certain high scoring sites (e.g. ranked 4) was caused by the conservative criteria we applied for a site to qualify as a putative binding site. Column 5 gives the observed ranking on basis of the transcriptional response towards a glnR knock out mutation (k.o.) as derived from [25] and the ranking of operons that are downregulated in a S. mutans glnR knock out after exposure to acid stress for 30 minutes [26]. The ranking score was calculated by dividing the fold change in the glnR mutant by the fold change in the wild-type. Column 1 (a): In some strains the arcA and glnQ ORFs have not been called. The published sequence of strain R6 suggests $\operatorname{arcA}$ and glnQ are truncated in this strain. Column 4 (b): The composition of the binding site upstream of $\operatorname{arcAB}$ and glnQHMP varies between strains.

* Although [25] studied the effects in strain D39, the used microarrays were based on strains TIGR4 and R6. For reasons of comparison we have therefore listed the locus tags in strain TIGR4.

encoding variants $g \ln P^{H} Q$ or $g \ln Q H M P$ were identified, whereas this association appeared to be replaced by one with the sodium/proton amino acid symporters encoded by glt $T$ (glutamate, [47]) and alsT [15] in various species within the family of the Bacillaceae. The AlsT protein is very similar to $\mathrm{GlnT}$, a cation-glutamine symporter, i.e. showing a high degree of sequence conservation and having about the same length and the same number of predicted transmembrane helices. Although the protein is sometimes referred to as an alanine transporter, AlsT could well be a cation-glutamine or asparagine symporter.

Other associations that were conserved included that with the $g d h$ gene (encoding glutamate dehydrogenase) and the citBZ-icd operon (encoding aconitase, citrate synthase and isocitrate dehydrogenase [24]) in many Streptococci, the ure $A B C$ operon (encoding urease [64]) and the nasDEF operon (encoding nitrite reductase [18]) in several Bacillus species and with several genes involved in purine and asparagine/aspartate transport and metabolism (e.g. pucI and pucH (encoding an allantoin transporter and allantoinase, respectively [20]), ywo $C D$ (encoding an amidase and a transport protein), ans $A$ and ans $Z$ (both encoding asparaginase [38], asp $A$ (encoding aspartase) and asn $A$ (encoding aspartate-ammonia ligase).
We also found a clear GlnR-binding site upstream of several genes involved in regulation, for instance of $m c p$ (chemotaxis, found in several Geobacillus species) and of the $y c s F G I-k i p I A R-y c s K$ operon (cellular development, found in several Bacillus species). In the initial description of the $y c s F G I-k i p I A R-y c s K$ operon [65], ycsF was related to the lactam (e.g. 2-pyrrolidinone) utilization gene lamB of Aspergillus nidulans [66], and kipA (orf12) was related to a urea amidolyase of yeast. Later, KipI was identified as a protein inhibitor of auto-phosphorylation of kinase $\mathrm{A}$, the sensor histidine kinase responsible for processing post-exponential phase information and for providing phosphate input to the phosphorelay that activates developmental transcription via phosphorylated Spo0A, and KipA as a protein that counteracts the inhibition [63]. YcsG showed similarity to BraB (branched chain amino acid transport system II) of Pseudomonas aeruginosa [67]. The operon was found repressed upon growth on good nitrogen sources like ammonia and glutamine and derepressed on poor nitrogen sources [68], in line with repression mediated by GlnR. The association with the $y c s F G I-k i p I A R-y c s K$ operon connects GlnR-mediated regulation to the regulation of sporulation in some Bacilli. 
Table 4 Distribution and function of additional genes-operons that are putatively linked to GlnR-mediated regulation

\begin{tabular}{|c|c|c|}
\hline species & gene/operon & annotation (literature) \\
\hline $\begin{array}{l}\text { A. flavithermus, G. C56-R3, G. kaustophilus, G. Y412MC61, L. seeligeri, } \\
\text { P. JDR2 }\end{array}$ & $m c p$ & regulation of chemotaxis \\
\hline B. megaterium, G. kaustophilus, G. Y412MC61, P. JDR2, P. polymyxa & pucR & $\begin{array}{l}\text { regulation of puc operon (purine catabolism) } \\
\text { [20] }\end{array}$ \\
\hline $\begin{array}{l}\text { B. amyloliquefaciens, B. atrophaeus, B. licheniformis, B. megaterium, B. } \\
\text { pumilus }\end{array}$ & ycsFGI-kipIAR-ycsK & includes regulation of sporulation [63] \\
\hline B. amyloliquefaciens, B. atrophaeus, L. salivarius & $g a b P$ & transport of gamma-aminobutyrate [19] \\
\hline $\begin{array}{l}\text { A. flavithermus, B. cereus, L. rhamnosus, O. oeni, P. JDR2, P. polymyxa, } \\
\text { S. gordonii, S. sanguinis }\end{array}$ & $o p p, d p p$ & transport of oligopeptide and/or dipeptide \\
\hline $\begin{array}{l}\text { B. amyloliquefaciens, B. atrophaeus, B. megaterium (2x), B. subtilis, G. } \\
\text { kaustophilus, G. Y412MC61 }\end{array}$ & pucl & transport of allantoin \\
\hline $\begin{array}{l}\text { B. amyloliquefaciens, B. atrophaeus (\&ywoB), B. subtilis (\&ywoB), P. } \\
\text { JDR2 (- ywoD) }\end{array}$ & $y w o C D$ & transport (ywoD) and hydrolysis (ywo $)$ \\
\hline $\begin{array}{l}\text { B. anthracis, B. cereus, B. thuringiensis, B. weihenstephanensis, P. JDR2 } \\
\text { (cpdB only) }\end{array}$ & $K 01238<>c p d B$ & $\begin{array}{l}\text { hydrolysis nucleoside 2',3'-cyclic } \\
\text { phosphate }+\mathrm{H}_{2} \mathrm{O}<=>\text { nucleoside 3'-phosphate }\end{array}$ \\
\hline L. seeligeri, O. oeni, Pb JDR2, P. polymyxa & ans $A$, ans $Z$ & L-asparagine $+\mathrm{H}_{2} \mathrm{O}<=>$ L-aspartate $+\mathrm{NH}_{3}[38]$ \\
\hline \multirow{2}{*}{$\begin{array}{l}\text { B. amyloliquefaciens, B. atrophaeus, B. licheniformis, B. pumilus, B. } \\
\text { subtilis }\end{array}$} & \multirow[t]{2}{*}{$\arg C$} & N-Acetyl-L-glutamate 5-semialdehyde $<=>$ \\
\hline & & N-Acetyl-L-glutamate 5-phosphate \\
\hline L. plantarum, L. rhamnosus, L. citreum & aspA & L-aspartate $<=>$ fumarate $+\mathrm{NH}_{3}$ \\
\hline S. mutans, S. gordonii, S. sanguinis, S. suis, S. thermophilus & citZ-citB-idh & conversion of citrate to alpha-ketoglutarate [24] \\
\hline $\begin{array}{l}\text { B. amyloliquefaciens, B. atrophaeus, B. megaterium, B. pseudofirmus, } \\
\text { G. C56-T3, G. kaustophilus, G. Y412MC61, P. sp. JDR2 }\end{array}$ & nasDEF & reduction of nitrite to $\mathrm{NH}_{3}[18]$ \\
\hline \multirow[t]{2}{*}{ B. atrophaeus, B. subtilis, G. Y412MC61 } & \multirow[t]{2}{*}{ pucH } & allantoin $+\mathrm{H} 2 \mathrm{O}<=>$ allantoate [20] \\
\hline & & [pucF: allantoate $<=>$ ureidoglycolate $+2 \mathrm{NH} 3$ ] \\
\hline \multirow[t]{2}{*}{$\begin{array}{l}\text { B. anthracis }(B C), B \text {. cereus }(C), B \text {. thuringiensis }(B C), B \text {. } \\
\text { weihenstephanensis }(C), S \text {. mutans }(C)\end{array}$} & \multirow[t]{2}{*}{ thrBC } & $\begin{array}{l}\text { L-homoserine }+\mathrm{ATP}<=>\mathrm{O}- \\
\text { phosphohomoserine }+\mathrm{ADP} \mathrm{O}- \\
\text { phosphohomoserine }+\mathrm{H} 2 \mathrm{O}<=>\text { threonine }+\mathrm{P}\end{array}$ \\
\hline & & $\begin{array}{l}\text { [ilvA: threonine }<=>2 \text {-oxobutanoate }+\mathrm{NH} 3] \\
{[24]}\end{array}$ \\
\hline $\begin{array}{l}\text { B. amyloliquefaciens, B. megaterium, B. pseudofirmus, B. subtilis, } P \text {. } \\
\text { JDR2 }\end{array}$ & ure $A B C$ & urea $+\mathrm{H} 2 \mathrm{O}<=>\mathrm{CO} 2+2 \mathrm{NH} 3[64]$ \\
\hline
\end{tabular}

The related data can be found in Additional file 4 .

Another important finding was that in B. subtilis many operons related to the purine degradation pathway are controlled by GlnR and/or TnrA, like pucABCDE, pucH, pucI, pucJKLM and ureABC. The relation between purine catabolism and control by TnrA was established before experimentally. It was observed that a $\operatorname{tn} \mathrm{A}$ mutant strain could not use purines or its metabolic intermediates as a nitrogen source during nitrogen limited conditions [20]. Nevertheless, the extent to which both GlnR and TnrA are connected to the related operons is surprising.

We observed no clear dependency between the composition of the predicted GlnR regulon and the presence or absence of the other nitrogen-related regulators CodY and TnrA. For instance, there are only a few differences between the predicted GlnR regulon of B. subtilis and $B$. cereus suggesting that GlnR does not take over regulatory roles of TnrA. Similarly, the presence or absence of CodY does not seem to affect the size of the GlnR regulon in the Lactobacillaceae. In L. lactis, a species that has CodY, it was shown experimentally that at least three genes/operons $\left(a m t B, g \ln R A\right.$ and $\left.g \ln P^{H H}, Q\right)$ are repressed by $G \ln R$ [62]. We indeed identified clear GlnR-binding sites in the upstream region of these three genes/operons in L. lactis. In $L$. plantarum and $L$. monocytogenes, two species that lack CodY, the same genes/operons appear to be preceded by a GlnR-binding site and only a few additional genes were found connected to GlnR indicating that GlnR does not take over the role of CodY in these species. The predicted GlnR regulon was smallest, consisting of only $g \ln R A$, in the meat isolates Macrococcus caseolyticus (a CodY and GlnR containing Staphylococcus) and L. sakei (a GlnR containing Lactobacillus).

\section{Conclusions}

We have analyzed all sequenced Bacilli for the presence of genes encoding central nitrogen metabolism and transport of the related metabolites, and identified their connection 
to the nitrogen metabolism regulator GlnR. Although there is a considerable variety in the presence of the central enzymes GS, G, GDH and GOGAT, and in the number of available transport systems for the central nitrogen-related metabolites, the composition of the GlnR regulon is relatively invariable between species. Moreover, we hardly found an effect of the absence or presence of the other regulators CodY, TnrA and GltC on the size of the predicted GlnR regulon.

We made an initial conservative regulon prediction by restricting the regulatory association to those connections that are conserved between at least three species. In general, our findings are also in line with previous comparative in silico analysis performed on a limited number of species [27]. Careful redefinition of a specific GlnR-binding and a specific TnrA-binding motif caused a slight but clear separation in the predicted regulons. It is likely that the conserved A/Ts at the $3^{\prime}$ and $5^{\prime}$ end of the GlnR motif, which are absent in the TnrA motif, contribute significantly to the separation. For B. subtilis, S. pneumoniae, S. mutans and $L$. lactis our predictions complied with the available experimental data. Moreover, within the Bacilli we identified several new potential members of the GlnR regulon, including the $y w o C D$ operon and the $y c s F G I-k i p I A R-y c s K$ operon.

Our analysis confirmed that for most species the size of the GlnR regulon is relatively small. The main regulatory associations in the species of the class Bacilli are with the incorporation of ammonium into central metabolism (or with the production of ammonium at high glutamine concentrations!) via glutamine synthetase ( $\ln R A$ operon), and with ammonium $(a m t B-g \ln K)$ and glutamine/glutamate transport (i.e. via $g \ln Q H M P, g \ln P H Q, g l t T$, alsT). At the same time, the lesser conserved associations point to a somewhat broader role. Many of the conserved associations include genes that are either directly (e.g. ans $A, \operatorname{arcA}, \operatorname{asp} A$, $g d h$, nas $D E F$, ure $A B C$ ) or more indirectly (by controlling intermediate steps, e.g. citBZ-idh, $p u c H$, thrBC) relate to the intracellular production of ammonia or are related to the import of aminated compounds (e.g. gabP, opp-dpp, pucI, $y w o C D$ ). Thus, it appears that the main conserved role of GlnR is to prevent the influx and intracellular production of glutamine and ammonium under conditions of high nitrogen availability. The connection of GlnRmediated repression with the control of intracellular ammonia concentration is interesting. Such a role fits with the intrinsic need for tight control of ammonia levels as put forward by [43], who argue that transport of ammonia $\left(\mathrm{NH}_{4}^{+}\right)$should be tightly regulated to limit futile cycling by diffusion of ammonia out of the cell.

\section{Methods}

Data and tools

Complete genomic sequences and initial annotations were obtained from NCBI ([68]; June 2011). Multiple sequence alignments were made with ClustalX [69], and BioEdit [70] was used to analyze sequences and alignments. Specific bootstrapped neighbor-joining trees, with 'correction for multiple substitutions', were created using ClustalX and the trees were analyzed using LOFT [71] and Dendroscope [72]. The Microbial Genome Viewer 2.0 (http://mgv2.cmbi. ru.nl) was used to examine the function information within the genomic context. Frequency representations of aligned sequences were created with Weblogo [73]. Microarray data from $g \ln R$ gene knockouts in Streptococcus pneumoniae and Streptococcus mutans used in this research were extracted from the Gene Expression Omnibus from NCBI [74].

The raw data resulting from the various analyses can be found at http://www.cmbi.ru.nl/bamics/supplementary/GrootKormelinketal_2012_GlnRregulon/. Data file 1: GlnR and TnrA motifs used for SMS; data file 2: GlnR motif search in Bacilli (w/o Streptococci); data file 3: GlnR motif search in Streptococci; data file 4: GlnR and TnrA motif search in Bacillus subtilis.

\section{Classification and annotation of protein sequences}

To obtain all proteins of a certain family, a prominent representative was chosen (listed in the legend of Table 1) and a BLAST search [75] was performed (cut-off $<\mathrm{e}^{-5}$ ) on all publicly available sequenced Bacilli genomes. Then the list of collected sequences (given as Additional file 1) was inspected. For all enzymes, the sequences could be grouped into specific clusters based on BLAST e-value only. In practice we found a group of sequences with comparable (very) low e-values $\left(<\mathrm{e}^{-30}\right)$ separated from the rest of the sequences with considerably higher e-values (separation $<\mathrm{e}^{-15}$ ). In the case of the transcription regulators the separation remained clear, however with higher e-values due to a short length of the regulator protein sequence. In the case of the transporters, for the Amt-family (1.A.11), the DAACS-family (2.A.13) and the AGCS-family (2.A.25) an e-value cut-off also sufficed to collect all family members, whereas for the PAAT-family; 3.A.1.3 (ABC transport) the coding sequences of the putative glutamine/glutamate substrate binding domains were aligned, the alignment was inspected by eye, deviant sequences were removed, and a bootstrap neighbour joining tree was generated (see [76]). The tree was divided into clusters on basis of the branching. For each cluster, single species representatives were considered orthologous.

\section{Motif definition and Similar Motif Scoring (SMS)}

The upstream region of the conserved $\operatorname{gn} R A$ operon was retrieved for all species and the promoter region was aligned (see Figure 2). Then the conserved sequence upstream of the promoter was collected. For B. subtilis it was shown that this site is only involved in GlnR-mediated regulation [13]. The collection was used to generate a osition frequency scoring matrix for each taxonomic family 
(raw data file 1). It appeared that the frequency matrix was very similar for all species except for the Streptococci, where it was slightly different (illustrated in Figure 3). For the definition of a TnrA-specific binding site the upstream regions of genes whose transcription was shown to be activated by TnrA in B. subtilis (raw data file 1) were retrieved and the binding site was identified on basis of the published characteristic GlnR/TnrA motif and the short distance upstream of the promoter. The collection of sites was then used to generate a position frequency scoring matrix.

The position frequency matrices were used to identify potential binding sites in the analyzed genomes using a similarity search method formulated before by us [29]. The method relies on the fact that one of the most common practices observed in literature to reconcile prediction with experiment is to minimize the number of differences between the target and the query (or the 'consensus'). In fact, this criterion can be captured in a straightforward scoring using only the position frequency matrix: Given any number of input sequences of size $i$, the nucleotide frequency $f_{\mathrm{N}(\mathrm{j})}$ (where $\mathrm{N} \in \mathrm{A}, \mathrm{C}, \mathrm{T}, \mathrm{G}$; and frequency is in terms of fraction) at every position $\mathrm{j}=1$ to $i$ can be used directly to provide all target sequences of size $i$ with a score by just adding up the input-based frequencies that relate to the nucleotide composition of the target. Division of the score by the length of the sequence $i$ results in a 'similarity' score that can range from 0 to 1 . Dividing this number by the highest attainable score given the input matrix then yields a relative 'similarity' score. In case the input sequences are representative for high-affinity sites, the ranking of target sequences according to score should approximately correspond to a ranking based on affinity. The method was tested and appeared at least as good to identify putative regulatory elements on basis of known input motifs as the commonly used tool MAST [77], yet providing a similarity score that is far easier to interpret and use. We identified putative $G \ln R$ regulon members for all species on the basis of two simple criteria: i) a relative similarity score $>87 \%$; and ii) a position between 250 and 0 bases upstream of the predicted translation start. In some cases experimentally verified more distant sites were also included as well as known intergenic sites. The results are given in Additional file 4.

\section{Additional files}

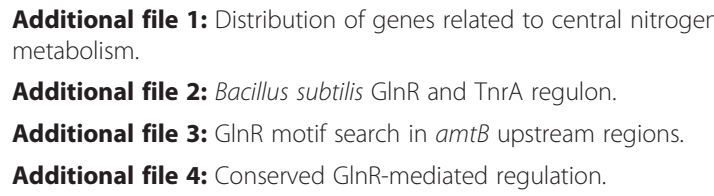

\section{Competing interests}

The authors declare that they have no competing interests.

\section{Acknowledgements}

This project was carried out within the research program of the Kluyver Centre for Genomics of Industrial Fermentation which is part of the Netherlands Genomics Initiative / Netherlands Organization for Scientific Research.

\section{Author details}

${ }^{1}$ Kluyver Centre for Genomics of Industrial Fermentation, P.O. Box 5057, 2600 GA Delft, The Netherlands. ${ }^{2} \mathrm{TI}$ Food and Nutrition, P.O. Box 557, 6700 AN Wageningen, The Netherlands. ${ }^{3}$ Laboratory of Microbiology, Wageningen University \& Research Centre, Dreijenplein 10, 6700 HB Wageningen, The Netherlands. ${ }^{4}$ Netherlands Bioinformatics Centre, P.O. Box 9101, 6500 HB Nijmegen, The Netherlands. ${ }^{5}$ Centre for Molecular and Biomolecular Informatics, NCMLS, Radboud University Nijmegen Medical Centre, P.O. Box 9101, 6500 HB Nijmegen, The Netherlands.

\section{Authors' contributions}

TGK conceived and designed the study, identified the GInR and TnrA motifs and predicted their regulons, and drafted and revised the manuscript. EK helped designing the study and performed motif searches. YH implemented and validated the motif search algorithm. LO helped designing the study and revising the manuscript. RJS and WMV coordinated the study and helped revising the manuscript. CF coordinated the study and helped designing it, carried out the classification and annotation of protein sequences and helped drafting and revising the manuscript. All authors read and approved the final manuscript

Received: 23 December 2011 Accepted: 20 March 2012

Published: 18 May 2012

\section{References}

1. Deuel TF, Prusiner $\mathrm{S}$ : Regulation of glutamine synthetase from Bacillus subtilis by divalent cations, feedback inhibitors, and L-glutamine. J Biol Chem 1974, 249(1):257-264.

2. Wray LV Jr, Zalieckas JM, Fisher SH: Bacillus subtilis glutamine synthetase controls gene expression through a protein-protein interaction with transcription factor TnrA. Cell 2001, 107(4):427-435.

3. Eisenberg D, Gill HS, Pfluegl GM, Rotstein SH: Structure-function relationships of glutamine synthetases. Biochim Biophys Acta 2000, 1477(1-2):122-145.

4. Fisher SH: Regulation of nitrogen metabolism in Bacillus subtilis: vive la difference! Mol Microbiol 1999, 32(2):223-232.

5. Bohannon DE, Sonenshein AL: Positive regulation of glutamate biosynthesis in Bacillus subtilis. J Bacteriol 1989, 171(9):4718-4727.

6. Belitsky BR, Janssen PJ, Sonenshein AL: Sites required for GltC-dependent regulation of Bacillus subtilis glutamate synthase expression. J Bacteriol 1995, 177(19):5686-5695.

7. Sonenshein AL: Control of key metabolic intersections in Bacillus subtilis. Nat Rev Microbiol 2007, 5(12):917-927.

8. Wray LV Jr, Fisher SH: Bacillus subtilis GInR contains an autoinhibitory C-terminal domain required for the interaction with glutamine synthetase. Mol Microbiol 2008, 68(2):277-285.

9. Kayumov A, Heinrich A, Fedorova K, Ilinskaya O, Forchhammer K: Interaction of the general transcription factor TnrA with the PII-like protein GlnK and glutamine synthetase in Bacillus subtilis. Febs J 2011, 278(10):1779-1789.

10. Heinrich A, Woyda K, Brauburger K, Meiss G, Detsch C, Stulke J, Forchhammer K: Interaction of the membrane-bound GInK-AmtB complex with the master regulator of nitrogen metabolism TnrA in Bacillus subtilis. J Biol Chem 2006, 281(46):34909-34917.

11. Castellen P, Rego FG, Portugal ME, Benelli EM: The Streptococcus mutans GlnR protein exhibits an increased affinity for the $g \ln R A$ operon promoter when bound to GInK. Braz J Med Biol Res 2011, 44(12):1202-1208.

12. Schreier HJ, Brown SW, Hirschi KD, Nomellini JF, Sonenshein AL: Regulation of Bacillus subtilis glutamine synthetase gene expression by the product of the glnR gene. J Mol Biol 1989, 210(1):51-63.

13. Zalieckas JM, Wray LV Jr, Fisher SH: Cross-regulation of the Bacillus subtilis glnRA and tnrA genes provides evidence for DNA binding site discrimination by GlnR and TnrA. J Bacterio/ 2006, 188(7):2578-2585. 
14. Brandenburg JL, Wray LV Jr, Beier L, Jarmer H, Saxild HH, Fisher SH: Roles of PucR, GlnR, and TnrA in regulating expression of the Bacillus subtilis ure P3 promoter. J Bacteriol 2002, 184(21):6060-6064.

15. Yoshida K, Yamaguchi $H$, Kinehara M, Ohki $Y H$, Nakaura $Y$, Fujita $Y$ : Identification of additional TnrA-regulated genes of Bacillus subtilis associated with a TnrA box. Mol Microbiol 2003, 49(1):157-165.

16. Nohno T, Saito T, Hong JS: Cloning and complete nucleotide sequence of the Escherichia coli glutamine permease operon ( $g / n H P Q)$. Mol Gen Genet 1986, 205(2):260-269.

17. Wray LV Jr, Zalieckas JM, Ferson AE, Fisher SH: Mutational analysis of the TnrA-binding sites in the Bacillus subtilis nrgAB and gabP promoter regions. J Bacteriol 1998, 180(11):2943-2949.

18. Nakano MM, Hoffmann T, Zhu Y, Jahn D: Nitrogen and oxygen regulation of Bacillus subtilis nasDEF encoding NADH-dependent nitrite reductase by TnrA and ResDE. J Bacterio/ 1998, 180(20):5344-5350.

19. Ferson AE, Wray LV Jr, Fisher SH: Expression of the Bacillus subtilis gabP gene is regulated independently in response to nitrogen and amino acid availability. Mol Microbiol 1996, 22(4):693-701.

20. Schultz AC, Nygaard P, Saxild HH: Functional analysis of 14 genes that constitute the purine catabolic pathway in Bacillus subtilis and evidence for a novel regulon controlled by the PucR transcription activator. J Bacteriol 2001, 183(11):3293-3302.

21. Belitsky BR, Wray LV Jr, Fisher SH, Bohannon DE, Sonenshein AL: Role of TnrA in nitrogen source-dependent repression of Bacillus subtilis glutamate synthase gene expression. J Bacteriol 2000, 182(21): 5939-5947.

22. Picossi S, Belitsky BR, Sonenshein AL: Molecular mechanism of the regulation of Bacillus subtilis gltAB expression by GltC. J Mol Biol 2007, 365(5):1298-1313.

23. Mader U, Hennig S, Hecker M, Homuth G: Transcriptional organization and posttranscriptional regulation of the Bacillus subtilis branched-chain amino acid biosynthesis genes. J Bacteriol 2004, 186(8):2240-2252.

24. Cvitkovitch DG, Gutierrez JA, Bleiweis AS: Role of the citrate pathway in glutamate biosynthesis by Streptococcus mutans. J Bacteriol 1997, 179(3):650-655.

25. Kloosterman TG, Hendriksen WT, Bijlsma JJ, Bootsma HJ, van Hijum SA, Kok J, Hermans PW, Kuipers OP: Regulation of glutamine and glutamate metabolism by GInR and GInA in Streptococcus pneumoniae. J Biol Chem 2006, 281(35):25097-25109.

26. Chen PM, Chen YY, Yu SL, Sher S, Lai CH, Chia JS: Role of GInR in acidmediated repression of genes encoding proteins involved in glutamine and glutamate metabolism in Streptococcus mutans. Appl Environ Microbiol 2010, 76(8):2478-2486.

27. Doroshchuk NA, Gel'fand MS, Rodionov DA: Regulation of nitrogen metabolism in gram-positive bacteria. Mol Biol (Mosk) 2006, 40(5):919-926.

28. Francke $C$, Kerkhoven $R$, Wels M, Siezen RJ: A generic approach to identify Transcription Factor-specific operator motifs; Inferences for Lacl-family mediated regulation in Lactobacillus plantarum WCFS1. BMC Genomics 2008, 9:145.

29. Francke C, Groot Kormelink T, Hagemeijer Y, Overmars L, Sluijter V, Moezelaar R, Siezen RJ: Comparative analyses imply that the enigmatic sigma factor 54 is a central controller of the bacterial exterior. BMC Genomics 2011, 12:385.

30. Fisher SH, Rosenkrantz MS, Sonenshein AL: Glutamine synthetase gene of Bacillus subtilis. Gene 1984, 32(3):427-438.

31. Belitsky BR, Sonenshein AL: Role and regulation of Bacillus subtilis glutamate dehydrogenase genes. J Bacteriol 1998, 180(23):6298-6305.

32. Commichau FM, Gunka K, Landmann JJ, Stulke J: Glutamate metabolism in Bacillus subtilis: gene expression and enzyme activities evolved to avoid futile cycles and to allow rapid responses to perturbations of the system. J Bacteriol 2008, 190(10):3557-3564.

33. Hosaka T, Ui S, Ohtsuki T, Mimura A, Ohkuma M, Kudo T: Characterization of the $\mathrm{NADH}$-linked acetylacetoin reductase/2,3-butanediol dehydrogenase gene from Bacillus cereus YUF-4. J Biosci Bioeng 2001, 91(6):539-544

34. Nicholson WL: The Bacillus subtilis ydjL (bdhA) gene encodes acetoin reductase/2,3-butanediol dehydrogenase. Appl Environ Microbiol 2008, 74(22):6832-6838.

35. Vanoni MA, Curti B: Glutamate synthase: a complex iron-sulfur flavoprotein. Cell Mol Life Sci 1999, 55(4):617-638.
36. Cedar $\mathrm{H}$, Schwartz JH: The asparagine synthetase of Escherichia coli. I. Biosynthetic role of the enzyme, purification, and characterization of the reaction products. J Biol Chem 1969, 244(15):4112-4121.

37. Scofield MA, Lewis WS, Schuster SM: Nucleotide sequence of Escherichia coli asn $B$ and deduced amino acid sequence of asparagine synthetase $B$. J Biol Chem 1990, 265(22):12895-12902.

38. Fisher SH, Wray LV Jr: Bacillus subtilis 168 contains two differentially regulated genes encoding L-asparaginase. J Bacterio/ 2002, 184(8):2148-2154.

39. Kim SI, Germond JE, Pridmore D, Soll D: Lactobacillus bulgaricus asparagine synthetase and asparaginyl-tRNA synthetase: coregulation by transcription antitermination? J Bacteriol 1996, 178(8):2459-2461.

40. Detsch C, Stulke J: Ammonium utilization in Bacillus subtilis: transport and regulatory functions of $\mathrm{NrgA}$ and NrgB. Microbiology 2003, 149(Pt 11):3289-3297.

41. Bolotin A, Wincker P, Mauger S, Jaillon O, Malarme K, Weissenbach J, Ehrlich SD, Sorokin A: The complete genome sequence of the lactic acid bacterium Lactococcus lactis ssp. lactis IL1403. Genome Res 2001, 11(5):731-753.

42. Saier MH Jr, Yen MR, Noto K, Tamang DG, Elkan C: The Transporter Classification Database: recent advances. Nucleic Acids Res 2009, 37(Database issue):D274-D278.

43. Boogerd FC, Ma H, Bruggeman FJ, van Heeswijk WC, Garcia-Contreras R, Molenaar D, Krab K, Westerhoff HV: AmtB-mediated NH3 transport in prokaryotes must be active and as a consequence regulation of transport by $\mathrm{GlnK}$ is mandatory to limit futile cycling of $\mathrm{NH} 4(+) / \mathrm{NH} 3$. FEBS Lett 2011, 585(1):23-28.

44. Schuurman-Wolters GK, Poolman B: Substrate specificity and ionic regulation of GInPQ from Lactococcus lactis. An ATP-binding cassette transporter with four extracytoplasmic substrate-binding domains. J Biol Chem 2005, 280(25):23785-23790.

45. Krastel K, Senadheera DB, Mair R, Downey JS, Goodman SD, Cvitkovitch DG: Characterization of a glutamate transporter operon, $g \ln Q H M P$, in Streptococcus mutans and its role in acid tolerance. J Bacteriol 2010, 192(4):984-993.

46. Wallace B, Yang YJ, Hong JS, Lum D: Cloning and sequencing of a gene encoding a glutamate and aspartate carrier of Escherichia coli K-12. J Bacteriol 1990, 172(6):3214-3220.

47. Gaillard I, Slotboom DJ, Knol J, Lolkema JS, Konings WN: Purification and reconstitution of the glutamate carrier GltT of the thermophilic bacterium Bacillus stearothermophilus. Biochemistry 1996, 35(19):6150-6156.

48. Groeneveld M, Weme RG, Duurkens RH, Slotboom DJ: Biochemical characterization of the C4-dicarboxylate transporter DctA from Bacillus subtilis. J Bacterio/ 2010, 192(11):2900-2907.

49. Burguiere P, Auger S, Hullo MF, Danchin A, Martin-Verstraete I: Three different systems participate in L-cystine uptake in Bacillus subtilis. J Bacteriol 2004, 186(15):4875-4884.

50. Satomura T, Shimura D, Asai K, Sadaie Y, Hirooka K, Fujita Y: Enhancement of glutamine utilization in Bacillus subtilis through the GlnK-GInL two-component regulatory system. J Bacteriol 2005, 187(14):4813-4821.

51. Gutowski JC, Schreier HJ: Interaction of the Bacillus subtilis glnRA repressor with operator and promoter sequences in vivo. J Bacterio/ 1992 174(3):671-681.

52. Nakano MM, Yang F, Hardin P, Zuber P: Nitrogen regulation of nasA and the nas $B$ operon, which encode genes required for nitrate assimilation in Bacillus subtilis. J Bacteriol 1995, 177(3):573-579.

53. Wray LV Jr, Zalieckas JM, Fisher SH: Purification and in vitro activities of the Bacillus subtilis TnrA transcription factor. J Mol Biol 2000, 300(1):29-40.

54. Wray LV Jr, Ferson AE, Fisher SH: Expression of the Bacillus subtilis ureABC operon is controlled by multiple regulatory factors including $\operatorname{CodY}, \mathrm{GlnR}$, TnrA, and SpoOH. J Bacteriol 1997, 179(17):5494-5501.

55. Schreier HJ, Rostkowski CA, Nomellini JF, Hirschi KD: Identification of DNA sequences involved in regulating Bacillus subtilis $g \ln R A$ expression by the nitrogen source. J Mol Biol 1991, 220(2):241-253.

56. de Been M, Bart MJ, Abee T, Siezen RJ, Francke C: The identification of response regulator-specific binding sites reveals new roles of two-component systems in Bacillus cereus and closely related low-GC Gram-positives. Environ Microbiol 2008, 10(10):2796-2809.

57. Wray LV Jr, Ferson AE, Rohrer K, Fisher SH: TnrA, a transcription factor 
required for global nitrogen regulation in Bacillus subtilis. Proc Natl Acad Sci U S A 1996, 93(17):8841-8845.

58. Robichon D, Arnaud M, Gardan R, Pragai Z, O'Reilly M, Rapoport G, Debarbouille M: Expression of a new operon from Bacillus subtilis, ykzB-ykoL, under the control of the TnrA and PhoP-phoR global regulators. J Bacteriol 2000, 182(5):1226-1231.

59. Beier L, Nygaard P, Jarmer H, Saxild HH: Transcription analysis of the Bacillus subtilis PucR regulon and identification of a cis-acting sequence required for PucR-regulated expression of genes involved in purine catabolism. J Bacteriol 2002, 184(12):3232-3241.

60. Tojo S, Satomura T, Morisaki K, Yoshida K, Hirooka K, Fujita Y: Negative transcriptional regulation of the ilv-leu operon for biosynthesis of branched-chain amino acids through the Bacillus subtilis global regulator TnrA. J Bacteriol 2004, 186(23):7971-7979.

61. Atkinson MR, Fisher SH: Identification of genes and gene products whose expression is activated during nitrogen-limited growth in Bacillus subtilis. J Bacteriol 1991, 173(1):23-27.

62. Larsen R, Kloosterman TG, Kok J, Kuipers OP: GlnR-mediated regulation of nitrogen metabolism in Lactococcus lactis. J Bacterio/ 2006, 188(13):4978-4982.

63. Wang L, Grau R, Perego M, Hoch JA: A novel histidine kinase inhibitor regulating development in Bacillus subtilis. Genes Dev 1997, 11(19):2569-2579.

64. Cruz-Ramos H, Glaser P, Wray LV Jr, Fisher SH: The Bacillus subtilis ureABC operon. J Bacteriol 1997, 179(10):3371-3373.

65. Akagawa E, Kurita K, Sugawara T, Nakamura K, Kasahara Y, Ogasawara N, Yamane K: Determination of a 17,484 bp nucleotide sequence around the 39 degrees region of the Bacillus subtilis chromosome and similarity analysis of the products of putative ORFs. Microbiology 1995, 141(Pt 12):3241-3245.

66. Richardson IB, Katz ME, Hynes MJ: Molecular characterization of the lam locus and sequences involved in regulation by the AmdR protein of Aspergillus nidulans. Mol Cell Biol 1992, 12(1):337-346.

67. Hoshino T, Kose K, Uratani Y: Cloning and nucleotide sequence of the gene braB coding for the sodium-coupled branched-chain amino acid carrier in Pseudomonas aeruginosa PAO. Mol Gen Genet 1990, 220(3):461-467.

68. Sayers EW, Barrett T, Benson DA, Bolton E, Bryant SH, Canese K, Chetvernin V, Church DM, DiCuccio M, Federhen S, et al: Database resources of the National Center for Biotechnology Information. Nucleic Acids Res 2011, 39(Database issue):D38-D51.

69. Thompson JD, Gibson TJ, Plewniak F, Jeanmougin F, Higgins DG: The CLUSTAL_X windows interface: flexible strategies for multiple sequence alignment aided by quality analysis tools. Nucleic Acids Res 1997, 25(24):4876-4882.

70. Tippmann HF: Analysis for free: comparing programs for sequence analysis. Brief Bioinform 2004, 5(1):82-87.

71. van der Heijden RT, Snel B, van Noort V, Huynen MA: Orthology prediction at scalable resolution by phylogenetic tree analysis. BMC Bioinformatics 2007, 8:83.

72. Huson DH, Richter DC, Rausch C, Dezulian T, Franz M, Rupp R: Dendroscope: An interactive viewer for large phylogenetic trees. BMC Bioinformatics 2007, 8:460.

73. Crooks GE, Hon G, Chandonia JM, Brenner SE: WebLogo: a sequence logo generator. Genome Res 2004, 14(6):1188-1190.

74. Barrett T, Troup DB, Wilhite SE, Ledoux P, Rudnev D, Evangelista C, Kim IF, Soboleva A, Tomashevsky M, Edgar R: NCBI GEO: mining tens of millions of expression profiles-database and tools update. Nucleic Acids Res 2007, 35(Database issue):D760-D765.

75. Altschul SF, Madden TL, Schaffer AA, Zhang J, Zhang Z, Miller W, Lipman DJ: Gapped BLAST and PSI-BLAST: a new generation of protein database search programs. Nucleic Acids Res 1997, 25(17):3389-3402.

76. Teusink B, van Enckevort FH, Francke C, Wiersma A, Wegkamp A, Smid EJ, Siezen RJ: In silico reconstruction of the metabolic pathways of Lactobacillus plantarum: comparing predictions of nutrient requirements with those from growth experiments. Appl Environ Microbiol 2005, 71(11):7253-7262.

77. Bailey TL, Boden M, Buske FA, Frith M, Grant CE, Clementi L, Ren J, Li WW, Noble WS: MEME SUITE: tools for motif discovery and searching. Nucleic Acids Res 2009, 37(Web Server issue):W202-W208. doi:10.1186/1471-2164-13-191

Cite this article as: Groot Kormelink et al: Comparative genome analysis of central nitrogen metabolism and its control by GInR in the class Bacilli. BMC Genomics 2012 13:191.

\section{Submit your next manuscript to BioMed Central and take full advantage of:}

- Convenient online submission

- Thorough peer review

- No space constraints or color figure charges

- Immediate publication on acceptance

- Inclusion in PubMed, CAS, Scopus and Google Scholar

- Research which is freely available for redistribution 